\title{
Alkaline Earth (Ca) and Transition Metal (Ni) Doping on the Transport Properties of $\mathrm{Y}_{1-x} \mathrm{Ca}_{x} \mathrm{Ba}_{2}\left(\mathrm{Cu}_{1-y} \mathrm{Ni}_{y}\right)_{3} \mathrm{O}_{7-\delta}$ Superconductors
}

\author{
Dinesh Varshney ${ }^{1,2}$, Arvind Yogi ${ }^{1}$, Neha Dodiya ${ }^{1}$, Irfan Mansuri ${ }^{1}$ \\ ${ }^{1}$ School of Physics, Vigyan Bhavan, Khandwa Road Campus, Devi Ahilya University, Indore, India \\ ${ }^{2}$ School of Instrumentation, USIC Bhavan, Khandwa Road Campus, Devi Ahilya University, Indore, India \\ E-mail:vdinesh33@rediffmail.com,vdinesh33@gmail.com \\ Received March 10, 2011; revised April 27, 2011; accepted May 18, 2011
}

\begin{abstract}
We report the results of $d c$ resistivity, $a c$ susceptibility, and thermopower study of partial substitution at $\mathrm{Y}$ ( $A$ site by $\mathrm{Ca})$ and at $\mathrm{Cu}(B$ site by $\mathrm{Ni})$ polycrystalline superconductors. The iodometric analysis reveals that the oxygen deficiency, $\delta$, for $\mathrm{YBa}_{2} \mathrm{Cu}_{3} \mathrm{O}_{7-\delta}$ (S-I), $\mathrm{Y}_{0.9} \mathrm{Ca}_{0.1} \mathrm{Ba}_{2} \mathrm{Cu}_{3} \mathrm{O}_{7-\delta}(\mathrm{S}-\mathrm{II}), \mathrm{Y}_{0.8} \mathrm{Ca}_{0.2} \mathrm{Ba}_{2} \mathrm{Cu}_{3} \mathrm{O}_{7-\delta}$ (S-III) and $\mathrm{Y}_{0.9} \mathrm{Ca}_{0.1} \mathrm{Ba}_{2}\left(\mathrm{Cu}_{0.99} \mathrm{Ni}_{0.01}\right)_{3} \mathrm{O}_{7-\delta}(\mathrm{S}-\mathrm{IV})$ samples are $0.16,0.30,0.39$ and 0.29 respectively. The $\mathrm{x}$-ray powder diffraction pattern indicates that all samples are in orthorhombic phase. The $d c$ resistivity, $a c$ susceptiblity and the thermopower measurements shows that the divalent Calcium doping at the trivalent $Y$ site and transition metal $\mathrm{Ni}$ doping at $\mathrm{Cu}$ site causes a suppression of the superconducting transition temperature $\left(T_{c}\right)$ from 89 to $81 \mathrm{~K}$. The $a c$ susceptibility confirms the ferromagnetic to antiferromagnetic phases at a defined $T_{c}$. The room temperature $S$ value increases for $\mathrm{Ca}$ substituted $\mathrm{YBa}_{2} \mathrm{Cu}_{3} \mathrm{O}_{7-\delta}$ while to that it decreases for $\mathrm{Y}_{0.9} \mathrm{Ca}_{0.1} \mathrm{Ba}_{2}\left(\mathrm{Cu}_{0.99} \mathrm{Ni}_{0.01}\right)_{3} \mathrm{O}_{6.71}$. The above feature is an indicative of enhanced number of mobile holes for the $\mathrm{Ca}$ doped $\mathrm{YBa}_{2} \mathrm{Cu}_{3} \mathrm{O}_{7-\delta}$, while to that the charge carrier density is reduced in simultaneous $A(\mathrm{Ca})$ and $B$ (Ni) site doped sample.
\end{abstract}

Keywords: Y-Based Superconductors, Doping Effect, Transport Properties

\section{Introduction}

Both alkaline earth and transition metal substitutions in cuprate superconductors are important for the phenomenon of superconductivity. The presence of magnetic impurities with variable concentration of carriers can cause changes of transport and electronic properties of the bulk system. All cuprate superconductors transformed from anti-ferromagnetic insulators to superconductors, and then to metals for enhanced doping. Thus the substitutional effects in the host compounds provides key insights into the electronic properties, phases, active phonon modes and symmetry of high- $T_{c}$ superconductivity and has been a major focus of high- $T_{c}$ research in superconductors, since its discovery [1].

The $\mathrm{YB}_{2} \mathrm{Cu}_{3} \mathrm{O}_{7-\delta}(\mathrm{YBCO})$ is an ideal superconductor and much research activities are focused mainly to investigate substitutional effects at $\mathrm{Y}(A)$ [2-5] site. The partial substitution of $\mathrm{Y}^{3+}$ by $\mathrm{Ca}^{2+}$ in $\mathrm{YBCO}$ changes the carrier concentration and influences the charge transfer from the
$\mathrm{Cu}-\mathrm{O}$ chains to the conducting $\mathrm{CuO}_{2}$ layers. Ideally, the Oxygen induces superconductivity in Ca-free YBCO while $\mathrm{Ca}$ does similarly in oxygen-deficient $\mathrm{YBCO}$. The optimal value for oxygen doping of YBCO is for $\delta=$ 6.92 with a $T_{c}$ of about $90 \mathrm{~K}$. The substitution of alkaline earth metals at $A$ site suppresses the superconducting $T_{c}$ from 90 to $80 \mathrm{~K}$ and has been a subject of immense importance.

On the other hand, the presence of transition metal impurities at $\mathrm{Cu}$ site $(B)$ in $\mathrm{YBa}_{2} \mathrm{Cu}_{3} \mathrm{O}_{7-\delta}$ cuprates as well increased oxygen deficiency further suppresses the transition temperature $\left(T_{c}\right)$ [6-11]. Less attention has been paid on simultaneous partial substitution of divalent alkaline earth at $\mathrm{Y}$ site $(A)$ and transition metal impurity at $\mathrm{Cu}$ site. It is now established that high- $T_{\mathrm{c}}$ cuprates as $\mathrm{YBa}_{2} \mathrm{Cu}_{3} \mathrm{O}_{7-\delta}$ show a large number of interesting features that includes antiferromagnetic, pseudogap, marginal Fermi liquid and ordinary Fermi liquid phases in addition to the superconducting phase, apart from the changes in the superconducting transition temperature $T_{\mathrm{c}}[12,13]$. It 
is worth to comment that $A$ and $B$ site doping in $\mathrm{YBa}_{2} \mathrm{Cu}_{3} \mathrm{O}_{7-\delta}$ superconductors will lead to an understanding of the effects of pair breaking, local moments, hole doping, ion size effects and disorder on the superconducting condensate.

The transport measurements as $d c$ electrical resistivity and thermopower are powerful probes to investigate the electronic states and phases of the host as well of the partially substituted YBCO either at $A$ or at $B$ site. It is inferred from the resistivity measurements that with the enhanced $\mathrm{Ca}$ doping at $\mathrm{Y}$ site, the resistivity of the samples decreases significantly $[3,4]$. Furthermore, $\mathrm{Ni}$ atoms substituted for $\mathrm{Cu}$ in $\mathrm{YBa}_{2} \mathrm{Cu}_{3} \mathrm{O}_{7-\delta}$ the resistivity for minimal doping decreases as compared to the parent compound, while to that for enhanced doping $(50 \%)$ the resistivity increases [7]. Substitution of $\mathrm{Cu}$ with metallic elements should produce substantial changes in the superconducting $T_{\mathrm{c}}$, which is also reflected in the transport properties. It is worth to mention that no systematic effort has been made to study the simultaneous substitutional effects in $\mathrm{YBa}_{2} \mathrm{Cu}_{3} \mathrm{O}_{7-\delta}$ with both $A$ and $B$ site doping.

The thermopower measurement is a technique that gives information about charge carriers. The $\mathrm{YB}_{2} \mathrm{Cu}_{3} \mathrm{O}_{7-\delta}$ superconductor contains both two-dimensional $\mathrm{CuO}_{2}$ planes and one-dimensional $\mathrm{CuO}$ chains. We may refer to the work of Bernhard and Tallon [14], who investigated the thermopower of polycrystalline

$\mathrm{Y}_{1-x} \mathrm{Ca}_{x} \mathrm{~B}_{2} \mathrm{Cu}_{3} \mathrm{O}_{7-\delta}[0 \leq x \leq 0.2$ and $0.04 \leq \delta \leq 0.98]$. The partial substitution introduces additional hole carriers into the $\mathrm{CuO}_{2}$ planes and makes the YBCO system access far into the overdoped regime [15]. The measured thermopower decreases almost linearly with temperature and a room temperature value of $S \sim 1-2 \mu \mathrm{V} / \mathrm{K}$ is documented and is argued for the $\mathrm{CuO}_{2}$ plane contribution. We must mention that no result has been documented in the literature about thermopower for $\mathrm{Ni}$ doping at $\mathrm{Cu}$ site in $\mathrm{YBa}_{2} \mathrm{Cu}_{3} \mathrm{O}_{7-\delta}$ superconductors. Henceforth, it is the purpose of the present paper to investigate the effect of transport properties on the simultaneous substitutional effects in $\mathrm{YB}_{2} \mathrm{Cu}_{3} \mathrm{O}_{7-\delta}$ superconductors.

The ion size effects and disorder on the superconducting state are substantial in YBCO superconductors and with these motivations, we aimed at the understanding of transport properties of both A [divalent $\mathrm{Ca}\left(4 s^{2}\right)$ at the trivalent $\left.\mathrm{Y}\left(4 d^{1} 5 s^{2}\right)\right]$ and $\mathrm{B}\left[\mathrm{Ni}\left(3 d^{8} 4 s^{2}\right)\right.$ at the $\left.\mathrm{Cu}\left(3 d^{10} 4 s^{1}\right)\right]$ site substitutions in $\mathrm{Y}_{1-x} \mathrm{Ca}_{x} \mathrm{Ba}_{2} \mathrm{Cu}_{3} \mathrm{O}_{7-\delta}(\mathrm{YCBCO})$ and $\mathrm{Y}_{1-x}$ $\mathrm{Ca}_{x} \mathrm{Ba}_{2} \mathrm{Cu}_{3-y} \mathrm{Ni}_{y} \mathrm{O}_{7-\delta}$ (YCBCNO) superconductors. We must mention that the individual effects have been reported earlier in the literature but a simultaneous effect of the Ca substitution and $\mathrm{Ni}$ doping has not been investigated. We perform the $d c$ resistivity, ac susceptibility, and thermopower measurements of $\mathrm{YBa}_{2} \mathrm{Cu}_{3} \mathrm{O}_{7-\delta}(\mathrm{S}-\mathrm{I})$, $\mathrm{Y}_{0.9} \mathrm{Ca}_{0.1} \mathrm{Ba}_{2} \mathrm{Cu}_{3} \mathrm{O}_{7-\delta} \quad(\mathrm{S}-\mathrm{II}), \quad \mathrm{Y}_{0.8} \mathrm{Ca}_{0.2} \mathrm{Ba}_{2} \mathrm{Cu}_{3} \mathrm{O}_{7-\delta} \quad(\mathrm{S}-\mathrm{III})$ and $\mathrm{Y}_{0.9} \mathrm{Ca}_{0.1} \mathrm{Ba}_{2}\left(\mathrm{Cu}_{0.99} \mathrm{Ni}_{0.01}\right)_{3} \mathrm{O}_{7-\delta}$ (S-IV) superconductors to delineate the substitutional effects both at $A$ and $B$ sites.

\section{Experimental Details}

Polycrystalline samples of $\mathrm{YB}_{2} \mathrm{Cu}_{3} \mathrm{O}_{7-\delta} \quad(\mathrm{YBCO})$, $\mathrm{Y}_{1-x} \mathrm{Ca}_{x} \mathrm{Ba}_{2} \mathrm{Cu}_{3} \mathrm{O}_{7-\delta}(\mathrm{YCBCO})$ and $\mathrm{Y}_{1-x} \mathrm{Ca}_{x} \mathrm{Ba}_{2} \mathrm{Cu}_{3-y}$

$\mathrm{Ni}_{y} \mathrm{O}_{7-\delta}$ (YCBCNO) [S-I - S-IV] were prepared for the experiments conducted by the solid-state ceramic route [16]. Powders of $\mathrm{Y}_{2} \mathrm{O}_{3}, \mathrm{BaCO}_{3}, \mathrm{CaCO}_{3}, \mathrm{Fe}_{2} \mathrm{O}_{3}$, and $\mathrm{NiO}$ in the stoichiometric ratios were mixed and annealing at temperatures $\left(850^{\circ} \mathrm{C}, 900^{\circ} \mathrm{C}\right)$ for 24 hours with intermediate grindings. The pellets were annealed at $950^{\circ} \mathrm{C}$ for $48 \mathrm{~h}$ in Oxygen atmosphere. The samples are cooled in oxygen at the rate of 5 to $10 \mathrm{C}$ per minute. A slow with preferably a long anneals enable to have a proper stoichiometry. The x-ray diffraction (XRD) measurements were carried out with $\mathrm{Cu} \mathrm{K} \alpha$ radiation using a Rigaku powder diffractometer equipped with a rotating anode scanning (0.01 step in $2 \theta$ ) over the angular range $10^{\circ}$ $80^{\circ}$ at room temperature generating $\mathrm{x}$-ray by $40 \mathrm{kV}$ and $100 \mathrm{~mA}$ power settings. For finding oxygen content we perform the improved iodometric titration reported [17].

The $d c$ resistivity and thermo power measurements of all prepared samples (SI-SIV) have been done to 10 $300 \mathrm{~K}$. The $d c$ resistivity measurements using four-probe method. Indium contacts are made on the polished surface of the sample. The sample is in the form of a rectangular rod. The SI temperature controller, Schlumberger multimeter and Advantest current source is used for the measurement. A vacuum of the order of $10^{-5} \mathrm{mbar}$ was maintained in the chamber with the help of turbo molecular pump assembly with silicon diode as the sensor. The $a c$ susceptibility measurements were carried out using home made setup [18]. In the critical region, the temperature was controlled to an accuracy of $0.01 \mathrm{~K}$ using commercial Lakeshore controllers DRC93CA and 340 .

\section{Results and Discussion}

The XRD patterns of $\mathrm{YBa}_{2} \mathrm{Cu}_{3} \mathrm{O}_{6.84}$ (S-I), $\mathrm{Y}_{0.90} \mathrm{Ca}_{0.10} \mathrm{Ba}_{2} \mathrm{Cu}_{3} \mathrm{O}_{6.7}(\mathrm{~S}-\mathrm{II}), \mathrm{Y}_{0.80} \mathrm{Ca}_{0.20} \mathrm{Ba}_{2} \mathrm{Cu}_{3} \mathrm{O}_{6.61}$ (S-III) and $\mathrm{Y}_{0.9} \mathrm{Ca}_{0.1} \mathrm{Ba}_{2}\left(\mathrm{Cu}_{0.99} \mathrm{Ni}_{0.01}\right)_{3} \mathrm{O}_{6.71}$ (S-IV) are shown in Figure 1. These are indexed in the orthorhombic phase and the deduced lattice parameters are illustrated in Table 1. The above lattice parameters are consistent with the earlier reports and corresponds to space group Pmmm $[3,7]$. It is inferred that the cell volume increases as $\mathrm{Ca}$ doping is partially enhanced at $\mathrm{Y}$ site, it further decreases for Ni doping at $\mathrm{Cu}$ site. The oxygen content in prepared samples is determined by the improved iodometric titration method [17]. We find the value of $\delta=0.16,0.30$, 
Table 1. Lattice parameters, cell volume and oxygen content of YBCO superconductors.

\begin{tabular}{llccccc}
\hline S. No. & Sample details & $\boldsymbol{a}(\boldsymbol{\AA})$ & $\boldsymbol{b}(\boldsymbol{\AA})$ & $\boldsymbol{c}(\boldsymbol{\AA})$ & $\mathbf{V}\left(\AA^{3}\right)$ & $\boldsymbol{\delta}$ \\
\hline 1. & $\mathrm{YBa}_{2} \mathrm{Cu}_{3} \mathrm{O}_{7-\delta}(\mathrm{SI})$ & 3.8067 & 3.8821 & 11.6789 & 172.59 & 0.16 \\
2. & $\mathrm{Y}_{0.9} \mathrm{Ca}_{0.1} \mathrm{Ba}_{2} \mathrm{Cu}_{3} \mathrm{O}_{7-\delta}(\mathrm{SII})$ & 3.8328 & 3.8764 & 11.7484 & 174.551 & 0.30 \\
3. & $\mathrm{Y}_{0.8} \mathrm{Ca}_{0.2} \mathrm{Ba}_{2} \mathrm{Cu}_{3} \mathrm{O}_{7-\delta}(\mathrm{SIII})$ & 3.8369 & 3.8784 & 11.7365 & 174.651 & 0.39 \\
4. & $\mathrm{Y}_{0.9} \mathrm{Ca}_{0.1} \mathrm{Ba}_{2}\left(\mathrm{Cu}_{0.99} \mathrm{Ni}_{0.01}\right)_{3} \mathrm{O}_{7-\delta}$ (SIV) & 3.8289 & 3.8864 & 11.6372 & 173.17 & 0.29 \\
\hline
\end{tabular}

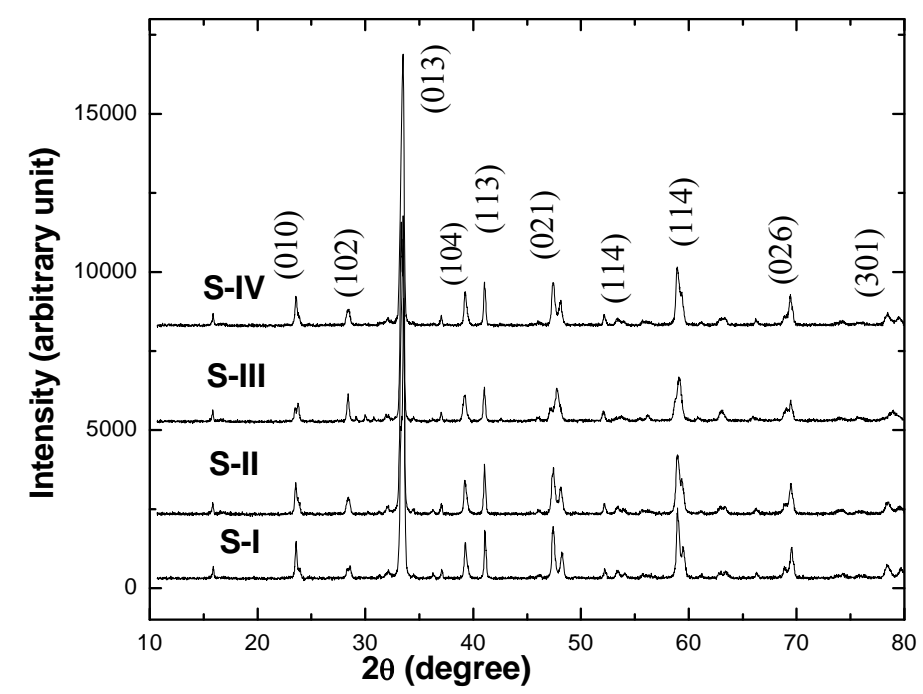

Figure 1. The $x$-ray diffraction pattern for samples S-I ( $\left.\mathrm{YBa}_{2} \mathrm{Cu}_{3} \mathrm{O}_{6.84}\right), \mathrm{S}-\mathrm{II}\left(\mathrm{Y}_{0.90} \mathrm{Ca}_{0.10} \mathrm{Ba}_{2} \mathrm{Cu}_{3} \mathrm{O}_{70}\right), \mathrm{S}-\mathrm{III}\left(\mathrm{Y}_{0.80} \mathrm{Ca}_{0.20} \mathrm{Ba}_{2} \mathrm{Cu}_{3} \mathrm{O}_{6.61}\right)$ and S-IV $\left(\mathrm{Y}_{0.9} \mathrm{Ca}_{0.1} \mathrm{Ba}_{2}\left(\mathrm{Cu}_{0.99} \mathrm{Ni}_{0.01}\right)_{3} \mathrm{O}_{6.71}\right)$.

0.39 and 0.29 for S-I to S-IV, respectively. We note the prepared polycrystalline samples are single phase and the oxygen content as determined from the Iodometric analysis is consistent with the earlier findings [3].

The experimental data for $d c$ resistivity of all these samples are illustrated in Figure 2. The superconducting transition temperature $T_{c}$ of samples S-I to S-IV is documented in Table 2. It is noticed that the $T_{c}$ decreases with the increased $\mathrm{Ca}$ doping at $\mathrm{Y}$ site and further decreases with the substitution of $\mathrm{Ni}$ at $\mathrm{Cu}$ site. The above is attributed to the fact that the substitution of $\mathrm{Ca}^{2+}$ for $\mathrm{Y}^{3+}$ in $\mathrm{YB}_{2} \mathrm{Cu}_{3} \mathrm{O}_{7-\delta}(\mathrm{YBCO})$ generates holes. The $\mathrm{Ca}$ substitution at $\mathrm{Y}$ site leads to counteract the hole-filling effect of oxygen vacancies, and the result is a significant increase in conducting hole concentration. The measured values of transition temperature $T_{c}$ are comparable to the reported data [14] for parent as well as $\mathrm{Ca}$ and $\mathrm{Ni}$ doping. Furthermore, above $T_{c}$, we have observed metallic behavior for all prepared superconductor samples. It is argued that in $\mathrm{Y}_{0.9} \mathrm{Ca}_{0.1} \mathrm{Ba}_{2}\left(\mathrm{Cu}_{0.99} \mathrm{Ni}_{0.01}\right)_{3} \mathrm{O}_{6.71}$ the transition metal ions (Ni) are distributed nearly equal between $\mathrm{Cu}$ (1) chain and $\mathrm{Cu}$ (2) plane sites [11]. The transition metal $\mathrm{Ni}$ ions act as hole filling agent and hence shows sharp transition at superconducting state with minimum oxygen deficiency as compared to the parent $\mathrm{YB}_{2} \mathrm{Cu}_{3} \mathrm{O}_{7-\delta}$ superconductor. Later on, the $a c$ susceptibility measure- ments of these samples were carried out to confirm the superconducting $T_{c}$ as shown in Figure 3. It is noticed that all the samples S-I to S-IV superconductors undergo a transition from paramagnetic to diamagnetic phase at a defined $T_{c}$. The $T_{c}$ values were determined from the inflexion points of the $\chi(T)$ curves consistent with the previous measurements [3].

The results of thermopower $(S)$ measurements for S-I to S-IV are shown in Figure 4. The value of $S$ at room temperature is found to be positive for all the samples, indicating them to be predominantly hole-type conductors. The measured values of thermopower at room temperature for samples S-I-S-IV are 8.3, 10.6, 19.6 and 7.3 $\mu \mathrm{V} \mathrm{K}^{-1}$, respectively. These values are consistent with the previously reported values [14]. It is inferred that the value of thermopower at room temperature increases monotonically with increasing $\mathrm{Ca} x$ for first three samples, implying that the number of mobile hole as carrier increases with increasing $x$ in the $\mathrm{Y}_{1-x} \mathrm{Ca}_{x} \mathrm{Ba}_{2} \mathrm{Cu}_{3} \mathrm{O}_{7-\delta}$ superconductor. The result for

$\mathrm{Y}_{0.9} \mathrm{Ca}_{0.1} \mathrm{Ba}_{2}\left(\mathrm{Cu}_{0.99} \mathrm{Ni}_{0.01}\right)_{3} \mathrm{O}_{6.71}$ superconductor could not be compared due to lack of data.

\section{Conclusions}

The present investigations explore the effect of doping 


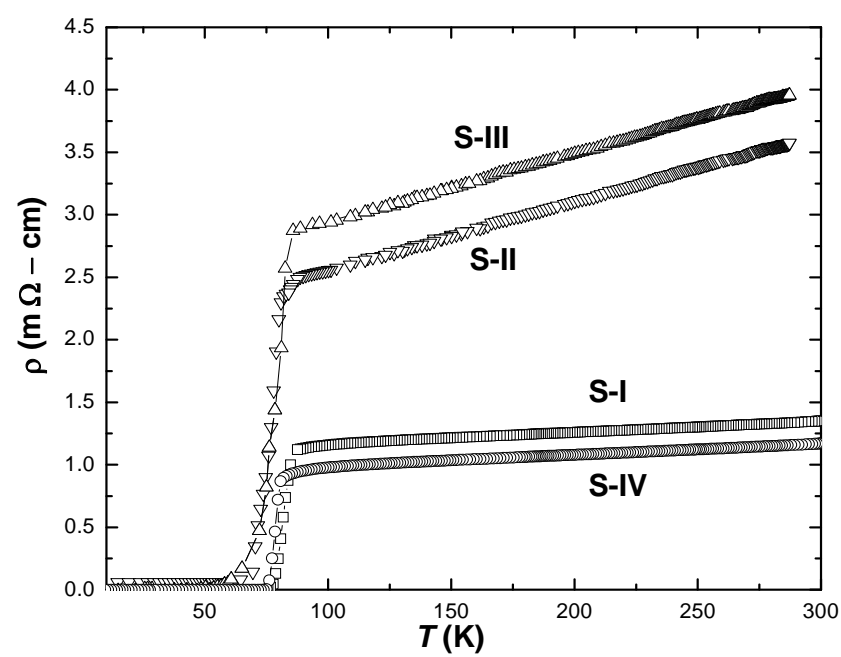

Figure 2. Variation of $d c$ resistivity as a function of temperature for samples S-I - S-IV.

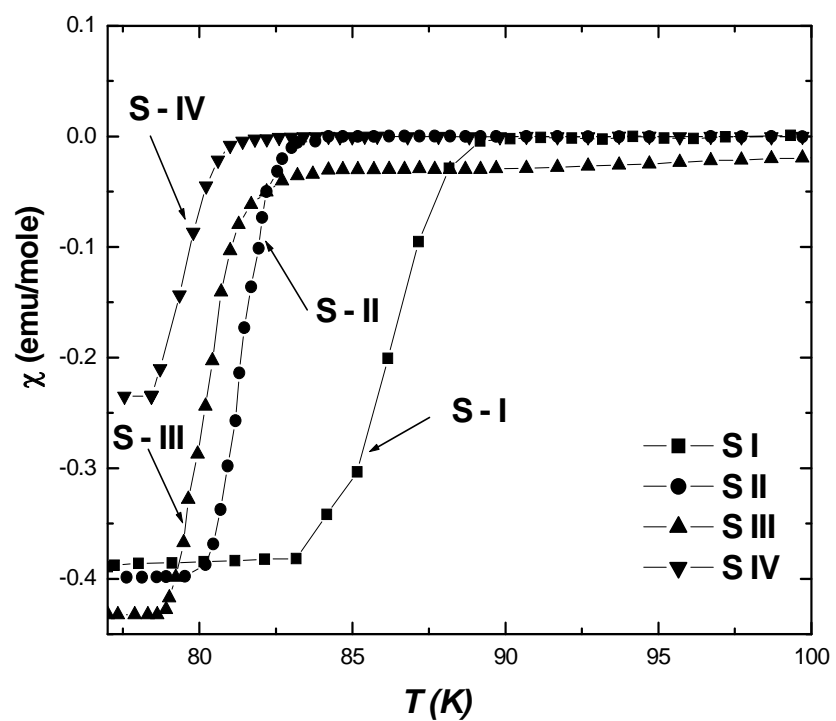

Figure 3. The ac susceptibility behavior with temperature for samples S-I - S-IV.

Table 2. Transition temperature $T_{c}$, oxygen content $(\delta)$ and resistivity $\rho$ values as $\rho(300 \mathrm{~K})$ and $\rho\left(T_{c}\right)$ for YBCO superconductors along with previous measurements [14].

\begin{tabular}{cccccccc}
\hline S. No. & Sample details & $\boldsymbol{T}_{\boldsymbol{c}}(\mathbf{K})$ & $\boldsymbol{\delta}$ & $\boldsymbol{T}_{\boldsymbol{c}}(\mathbf{K})$ & $\boldsymbol{\delta}$ & $\begin{array}{c}\boldsymbol{\rho}(\mathbf{3 0 0} \mathbf{K}) \\
(\mathbf{m} \boldsymbol{\Omega} \mathbf{c m})\end{array}$ & $\begin{array}{c}\boldsymbol{\rho}\left(\boldsymbol{T}_{\boldsymbol{c}}\right) \\
(\mathbf{m} \boldsymbol{\mathbf { c m }})\end{array}$ \\
\hline 1. & $\mathrm{YBa}_{2} \mathrm{Cu}_{3} \mathrm{O}_{7-\delta}(\mathrm{S}-\mathrm{I})$ & 89 & 0.16 & $93.5[14]$ & $0.12[14]$ & 1.35 & 1.12 \\
2. & $\mathrm{Y}_{0.9} \mathrm{Ca}_{0.1} \mathrm{Ba}_{2} \mathrm{Cu}_{3} \mathrm{O}_{7-\delta}(\mathrm{S}-\mathrm{II})$ & 83 & 0.30 & $87.9[14]$ & $0.26[14]$ & 3.56 & 2.45 \\
3. & $\mathrm{Y}_{0.8} \mathrm{Ca}_{0.2} \mathrm{Ba}_{2} \mathrm{Cu}_{3} \mathrm{O}_{7-\delta}(\mathrm{S}-\mathrm{III})$ & 82 & 0.39 & $85.5[14]$ & $0.38[14]$ & 3.94 & 2.87 \\
4. & $\mathrm{Y}_{0.9} \mathrm{Ca}_{0.1} \mathrm{Ba}_{2}\left(\mathrm{Cu}_{0.99} \mathrm{Ni}_{0.01}\right)_{3} \mathrm{O}_{7-\delta}(\mathrm{S}-\mathrm{IV})$ & 81 & 0.29 & & & 1.18 & 0.91 \\
\hline
\end{tabular}

[non magnetic $\mathrm{Ca}$ substitution at $\mathrm{Y}$ site and transition metal $\mathrm{Ni}$ at $\mathrm{Cu}$ site in $\mathrm{YBa}_{2} \mathrm{Cu}_{3} \mathrm{O}_{7-\delta}$ superconductors] on the structural, electrical, and magnetic properties. The $\mathrm{x}$-ray diffraction patterns of all samples were indexed in the orthorhombic phase with space group Pmmm. All the samples were found to be monophasic without any trace of impurity like $\mathrm{BaCuO}_{3}$ or related phases. The cell volume increases as $\mathrm{Ca}$ doping increases at $\mathrm{Y}$ site, it further decreases for $\mathrm{Ni}$ doping at $\mathrm{Cu}$ site. Resistivity and susceptiblity data shows the $T_{c}$ at $89,83,82$ and $81 \mathrm{~K}$ for S-I - S-IV samples, respectively. Divalent Calcium (Ca) doping at the trivalent $(\mathrm{Y})$ site and transition metal $\mathrm{Ni}$ doping at $\mathrm{Cu}$ site causes a suppression of the super- conducting transition temperature $\left(T_{c}\right)$ from 89 to $81 \mathrm{~K}$.

Above $T_{c}$, the resistivity data for all samples shows metallic behaviour but as $\mathrm{Ca}$ doping at $\mathrm{Y}$ site (S-II) 


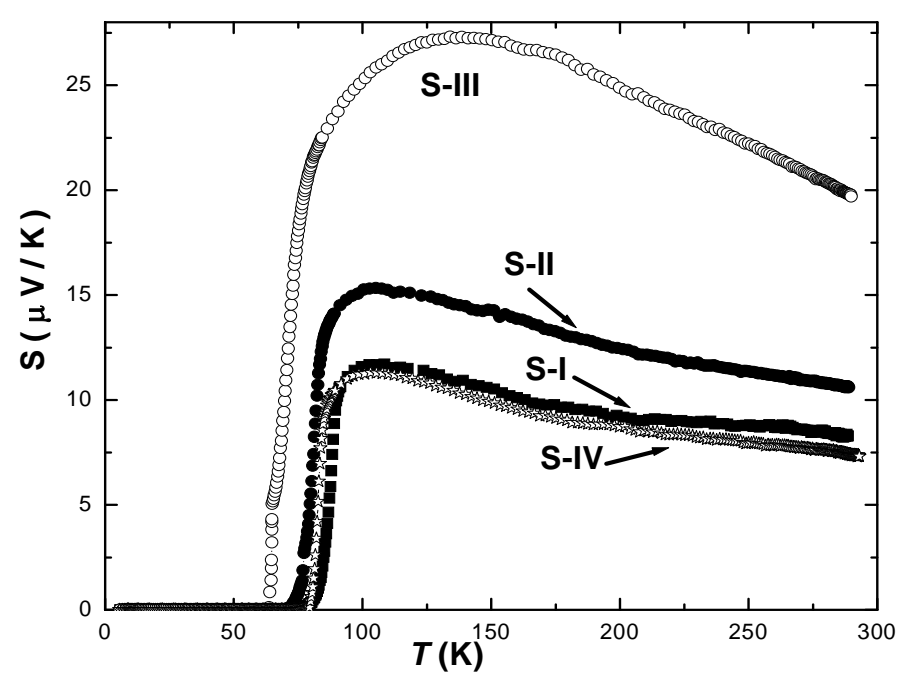

Figure 4. Variation of thermopower as function of temperature $(S)$ for samples S-I - S-IV.

compare to parent sample (S-I), the magnitude residual resistivity is larger and if further increase the doping of Ca concentration at $\mathrm{Y}$ site (S-III), then it also increases. The $B$ site Ni doping (S-IV) at $\mathrm{Cu}$, a metallic characteristic is noticed but residual resistivity decreases as compare to the parent sample (S-I). The $a c$ susceptibility measurements show a transition from ferromagnetic to antiferromagnetic phase at the well-defined $T_{c}$. The room temperature thermopower value increases with increased doping [S-I - S-III] while it decreases for simultaneous doping at $A$ and $B$ site [S-IV], indicating an enhanced number of mobile holes for first three samples and reduced charge carrier for $A$ and $B$ site doped S-IV sample.

\section{Acknowledgements}

Financial assistance from UGC, Delhi is gratefully acknowledged. Authors are thankful to UGC-DAE-CSR, Indore for providing facilities. We acknowledge Dr. V. Ganeshan, Dr. R. Rawat, Dr. R. J. Choudhary and Dr. V. Sathe for their support in carrying out measurements.

\section{References}

[1] J. G. Bednorz and K. A. Muller, "Possible highTc Superconductivity in the Ba-La-Cu-O System," Zeitschrift für Physik B, Vol. 64, No. 2, 1986, pp. 189- 193.

[2] W Guan, J. C. Chen and S. H. Cheng, "Ion-Size Effect on Transport Properties in $\mathrm{R}_{0.9} \mathrm{Ca} 0.1 \mathrm{Ba}_{2} \mathrm{Cu}_{3} \mathrm{O}_{7-\delta}$ Systems ( $\mathrm{R}$ = Tm, Ho, Gd, and Nd)," Physical Review B, Vol. 54, No. 5, 1996, pp. 3580-3588. doi:10.1103/PhysRevB.54.3580

[3] V. P. S. Awana, A. Tulapurkar, S. K. Mallik and A. V. Narlikar, "Role of $\mathrm{Ca}$ in Enhancing the Superconductivity of $\mathrm{YBa}_{2} \mathrm{Cu}_{3} \mathrm{O}_{7-y}$," Physical Review B, Vol. 50, No. 1, 1994, pp. 594-596. doi:10.1103/PhysRevB.50.594
[4] B. Fisher, J. Genossar, C. G. Kuper, L. Patlagan, G. M. Reisner and A. Knizhnik, "Effects of Substituting Calcium for Yttrium on the Properties of YBa2Cu3O7- $\delta$," Physical Review B, Vol. 47, No. 10, 1993, pp. 6054-6059. doi:10.1103/PhysRevB.47.6054

[5] R. J. Tellon and L. F. Flower, "Stoichiometric $\mathrm{YBa}_{2} \mathrm{Cu}_{3} \mathrm{O}_{7}$ is Overdoped," Physica C, Vol. 204, No. 3-4, 1993, pp. 237-246. doi:10.1016/0921-4534(93)91005-G

[6] G. Xiao, F. H. Streitz, A. Gavrin, Y. W. Du and C. L. Chien, "Effect of Transition-Metal Elements on the Superconductivity of Y-Ba-Cu-O," Physical Review B, Vol. 35 , No. 16,1987 , pp. 8782-8784. doi:10.1103/PhysRevB.35.8782

[7] J. M. Tarascon, P. Barboux, P. F. Miceli, L. H. Greene and G. H. Hull, "Structural and Physical Properties of the Metal (M) Substituted $\mathrm{YBa}_{2} \mathrm{Cu}_{3-x} \mathrm{M}_{\mathrm{x}} \mathrm{O}_{7-y}$ Perovskite," Physical Review B, Vol. 37, No. 13, 1988, pp. 7458-7469. doi:10.1103/PhysRevB.37.7458

[8] R. L. Neiman, J. Giapintzakis and D. M. Ginsberg, "Transition Temperature and Irreversibility Line of $\mathrm{Co}$ balt-Doped Single-Crystal $\mathrm{YBa}_{2} \mathrm{Cu}_{3} \mathrm{O}_{7-\delta}$ : The Effect of High-Pressure Oxygen Annealing," Physical Review B, Vol. 50, 1994, pp. 16028-16032. doi:10.1103/PhysRevB.50.16028

[9] J. T. Kim, J. Giapintzakis and D. M. Ginsberg, "Sign Reversal of the Hall Effect in Superconducting YBa2 $\left(\mathrm{Cu}_{1-x} \mathrm{Ni}_{x}\right)_{3} \mathrm{O}_{7-\delta}$ Single Crystals," Physical Review B, Vol. 53, No. 9, 1996, pp. 5922-5826. doi:10.1103/PhysRevB.53.5922

[10] E. R. Ulm and T. R. Lemberger, "Sign Reversal of the Hall Effect in Superconducting $\mathrm{YBa}_{2}\left(\mathrm{Cu}_{1-x} \mathrm{Ni}_{x}\right)_{3} \mathrm{O}_{7-\delta}$ Single Crystals," Physical Review B, Vol. 53, No. 9, 1996, pp. 11352-11355. doi:10.1103/PhysRevB.53.11352

[11] B. D. Padalia, S. J. Gurman, P. K. Mehta and O. Prakash, "Extended X-Ray Absorption Fine-Structure Studies of $3 \mathrm{~d}$ Ions in $\mathrm{YBa}_{2}\left(\mathrm{Cu}_{1-x} \mathrm{M}_{x}\right)_{3} \mathrm{O}_{7}-$ delta $(\mathrm{x}<$ or $=0.10 ; \mathrm{M}$ Identical to $\mathrm{Mn}, \mathrm{Fe}, \mathrm{Co}, \mathrm{Ni}$ and $\mathrm{Zn}$ )," Journal of Physics: 
Condensed Matter, Vol. 4, No. 33, 1992, p. 6865. doi:10.1088/0953-8984/4/33/001

[12] M. A. Kastner, R. J. Birgeneau, G. Shirane and Y. Endoh, "Magnetic, Transport, and Optical Properties of Monolayer Copper Oxides," Reviews of Modern Physics, Vol. 70, No. 3, 1998, pp. 897-928;

[13] T. Timusk and B. Statt, "The Pseudogap in High-Temperature Superconductors: An Experimental Survey," Re-ports on Progress in Physics, Vol. 62, No.1, 1999, pp. 61- 122.

[14] C. Bernhard and J. L. Tallon, "Thermoelectric Power of $\mathrm{Y}_{1-x} \mathrm{Ca}_{x} \mathrm{Ba}_{2} \mathrm{Cu}_{3} \mathrm{O}_{7-\delta}$ : Contributions from $\mathrm{CuO}_{2}$ Planes and CuO Chains," Physical Review B, Vol. 54, No. 13, 1996, pp. 10201-10209. doi:10.1103/PhysRevB.54.10201

[15] J. R. Cooper and J. W. Loram, "Some Correlations between the Thermodynamic and Transport Properties of High $T_{\mathrm{c}}$ Oxides in the Normal State," Journal de Phy- sique I France, Vol. 6, No. 12, 1996, pp. 2237-2263.

[16] D. Varshney, I. Mansuri and N. Kaurav, "Effect of Electron/Hole Doping on the Transport Properties of Lanthanum Manganites $\mathrm{LaMnO}_{3}$," Journal of Physics: Condensed Matter, Vol. 19, No. 24, 2007, p. 246211 doi:10.1088/0953-8984/19/24/246211

[17] W. M. Chen, C. C. Lam, J. F. Geng, L. Y. Li, K. C. Hung and X. Jin, "A New Calculating Formula of Iodometric Titration For High $T_{\mathrm{c}}$ Superconductors," Physica $C$, Vol. 270, No. 1-2, 1996, pp. 155-158. doi:10.1016/0921-4534(96)00497-2

[18] R. V. Krishnan and A. Banerjee, "Harmonic Detection of Multipole Moments and Absolute Calibration in a Simple, Low-Cost Vibrating Sample Magnetometer," Review of Scientific Instruments, Vol. 70, No. 1, 1999, pp. 85-91. $\underline{\text { doi: } 10.1063 / 1.1149545}$ 